\title{
Inadequate Humoral Immunogenicity to Recombinant Hepatitis B Virus Vaccine in Biliary Atresia Children
}

\author{
JIA-FENG WU, YEN-HSUAN NI, HUEY-LING CHEN, HONG-YUAN HSU, HONG-SHIEE LAI, AND MEI-HWEI CHANG
}

Departments of Pediatrics [J.-F.W., Y.-H.N., H.-L.C., H.-Y.H., M.-H.C.], and Pediatric Surgery [H.-S.L.], National Taiwan University, Taipei 100, Taiwan, China

\begin{abstract}
This study aimed to investigate the primary immunogenicity and the long-term efficacy of recombinant hepatitis B virus (HBV) vaccine in biliary atresia (BA) children. Fifty BA infants (age, $11 \pm 3.9 \mathrm{mo}$ ), and $23 \mathrm{BA}$ patients at childhood (age, $8.5 \pm 0.22 \mathrm{y}$ ) were included for the evaluation of HBV surface antibody (anti-HBs) levels after three doses of recombinant HBV vaccine immunization. Age- and gender-matched healthy infants $(n=50)$ and children $(n=23)$ were enrolled as the control group. Serum samples of the study populations were collected for HBV seromarkers determination. In the absence of hepatitis $\mathrm{B}$ virus core antibody and HBV surface antigen, serum anti-HBs level above 10 IU/L was considered adequate immunogenicity to HBV vaccine. The prevalence of adequate anti-HBs levels after recombinant $\mathrm{HBV}$ vaccine in BA infants was significantly lower than those of the controls $(p=0.006)$. There was no difference in the prevalence between childhood BA patients and their matched controls $(p=0.538)$. In conclusion, adequate primary humoral immunity after the standard doses of recombinant HBV vaccine in BA infants is hard to establish. However, once immunity is acquired, BA children have adequate anti-HBs titer in the long run.
\end{abstract}

(Pediatr Res 64: 100-104, 2008)

$\mathrm{B}$ iliary atresia (BA) is a lethal cholestatic liver disease of early infancy and is the leading cause of liver transplantation (LT) in children $(1,2)$. In such children, hepatotropic viral infections such as hepatitis B virus (HBV) may induce further hepatocyte damage (3). In an HBV hyper-endemic area such as Taiwan, the efficacy of vaccination against HBV infection is an important medical issue in BA patients.

With the implementation of the universal HBV vaccination program for infants in Taiwan in 1984, the prevalence of HBV infection decreased significantly in the pediatric population (4-7). However, the prevalence of HBV infection in the population born before this mass HBV vaccination remained high, and these subjects might serve as the source of HBV infection. Because of the shortage of donor organs, some donors with negative hepatitis B virus surface antigen (HBsAg) and positive hepatitis B virus core antibody (anti$\mathrm{HBc}$ ) still serve as living related liver donors in Taiwan (8). Recipients with these liver grafts are prone to the development of de novo HBV infection after LT, and adequate

Received October 9, 2007; accepted February 13, 2008.

Correspondence: Yen-Hsuan Ni, M.D., Ph.D., Department of Pediatrics, National Taiwan University Hospital, No. 7 Chung-Shan S. Road, Taipei 100, Taiwan; e-mail: yhni@ntu.edu.tw

This work was supported by the grant from the National Taiwan University Hospital, Taiwan (NTUH-96-N03) and the Children Liver Foundation of Taiwan. serum hepatitis B virus surface antibody (anti-HBs) titers may prevent this complication (9).

Adequate humoral immune response to $\mathrm{HBV}$ vaccines is a T-lymphocyte dependent immune reaction $(10,11)$. Impaired T-lymphocyte function among BA patients with jaundice has been demonstrated in our previous study (12). The primary immune response and long-term efficacy of T-lymphocyte dependent HBV vaccine in BA children need to be further investigated.

The response rate to $\mathrm{HBV}$ vaccine in BA children is only $73.3 \%$ in a previous study, which is much lower than that of the general population (3). However, the majority (85.5\%) of children in the previous series received plasma-derived vaccine, and only eight children (14.5\%) received recombinant HBV vaccine (3). Because there has been no study that assessed either the primary immune response or the long-term efficacy of recombinant $\mathrm{HBV}$ vaccine in BA patients, this study was conducted.

\section{METHODS}

Subjects and study design. This was a cross-sectional study where two groups of BA patients were recruited: (1) BA patients at infancy (7-18 mo), to assess the primary immune response to recombinant $\mathrm{HBV}$ vaccine, and (2) BA patients at later childhood (7-10 y), to assess the long-term efficacy of recombinant HBV vaccine. From 1994 to 2007, a total of 73 infants diagnosed as BA after a Kasai operation ( 27 boys and 46 girls) aged between 7 and 18 mo who underwent venous blood sampling at the Department of Pediatrics, National Taiwan University Hospital with permission from their parents were enrolled into our infant BA group. Another 40 BA children aged 7-10 y (16 boys and 24 girls) were enrolled as the childhood BA group. ${ }^{1}$

None of the patients received transplantation before our assessment. The diagnosis of BA was established by intraoperative cholangiogram. There was only one child diagnosed as BA with splenic malformation in our series. This child received two doses of $\mathrm{HBV}$ vaccine, and was not eligible to be included into statistic analysis. Twenty-three BA infants (31.5\%) and 17 childhood BA patients $(42.5 \%)$ who received less than three doses of recombinant HBV vaccine were defined as incomplete $\mathrm{HBV}$ vaccination, and were excluded from this study. The remaining $50 \mathrm{BA}$ infants $(68.5 \%)$ and 23 childhood BA patients $(57.5 \%)$ who received three doses of recombinant $\mathrm{HBV}$ vaccines were the subjects for the final analysis.

Age- and gender-matched healthy controls aged between 7 and $18 \mathrm{mo}(n=$ $50)$ and $7-10$ y $(n=23)$ were randomly sampled from our previous HBV seroepidemiologic survey in Taiwan, and were negative for both HBsAg and anti-HBc markers (7). All of the controls had received three doses of recombinant $\mathrm{HBV}$ vaccines on routine schedule.

Abbreviations: ALT, alanine aminotransferase; Anti-HBs, hepatitis B virus surface antibody; Anti-HBc, hepatitis B virus core antibody; BA, biliary atresia; HBV, hepatitis B virus; HBIG, HBV immunoglobulin; HBsAg, hepatitis B virus surface antigen; LT, liver transplantation 
Immunization history for HBV in these children was confirmed through a review of medical records, vaccine registration system from Centers for Disease Control of Taiwan, as well as the personal vaccine booklet record provided by the Department of Health of Taiwan.

The nutritional status of all of the study subjects, including body weight, body length, body mass index (BMI), and serum albumin levels were measured at the time of blood sampling. The study protocol was approved by the institutional review board and the ethics committee of this hospital. Informed consent was obtained for every child in this study.

$H B V$ vaccination schedules. All children in Taiwan received recombinant HBV vaccines with either $5 \mu \mathrm{g}$ of Recombivax-HB (Merck, NJ) or $20 \mu \mathrm{g}$ of Engerix-B (GSK, Middlesex, UK) at birth, and at ages 1 and 6 mo as the standard vaccine schedule after July 1, 1992. At the same time, 100 IU (0.5 $\mathrm{mL}$ ) of $\mathrm{HBV}$ immunoglobulin (HBIG) was also given within $24 \mathrm{~h}$ of delivery to infants whose mothers had HBV e antigen or serum HBsAg titers above 2560 by reverse-passive hemagglutinin assay.

Subjects who received either the first dose of HBV vaccine before $7 \mathrm{~d}$ of age, the second dose between 1 and $1.5 \mathrm{mo}$, and the third dose between 6 and 6.5 mo was defined as on-schedule HBV vaccines. The rest were defined as out-of-schedule HBV vaccines. All of the children were born after 1993 and received recombinant $\mathrm{HBV}$ vaccines for active immunization against $\mathrm{HBV}$ infection. In the childhood BA patients $(7-10 \mathrm{y})$, no patients received a booster dose of $\mathrm{HBV}$ vaccine after the standard three doses of recombinant HBV vaccine before our assessment.

Blood analysis. These serum samples were processed and stored at $-80^{\circ} \mathrm{C}$ refrigeration within $12 \mathrm{~h}$ of blood sampling. These stored serum samples were then evaluated for serum total bilirubin, albumin, and alanine aminotransferase (ALT) levels by an auto-analyzer (Hitachi 736, Tokyo, Japan).

$\boldsymbol{H B V}$ serologic tests. Blood samples were obtained at least 1 mo after the third dose of recombinant HBV vaccine in both infant (median, $5 \mathrm{mo}$; range, 1-12 mo) and childhood groups (median, $8 \mathrm{y}$; range, 5.5-9.5 y). HBV seromarkers, including, HBsAg, anti-HBs, and anti-HBc were assessed by radioimmunoassay (Abbott Laboratories, North Chicago, IL) available at the Department of Laboratory Medicine, National Taiwan University Hospital.

In the absence of anti-HBc and HBsAg, children with serum anti-HBs titer below $10 \mathrm{IU} / \mathrm{L}$ after the three doses of recombinant $\mathrm{HBV}$ vaccine were defined as inadequate immune response to HBV vaccine. Serum anti-HBs level $\geq 10$ IU/L was defined as adequate response to recombinant HBV vaccine. Among adequate HBV vaccine responders, serum anti-HBs level between 10 and $100 \mathrm{IU} / \mathrm{L}$ was defined as low response whereas above 100 IU/L as good immunogenicity (3).

Statistical analysis. Statistical analyses were performed using the STATA package software (StataCorp LP, TX). One-way analysis of variance test, $t$ test, and the Mann-Whitney U test were used for analysis of all continuous data. $\chi^{2}$ or Fisher's exact test were used for categorical variables and outcomes. Logistic regression model was used to identify factors associated with the failure of HBV vaccine. Backward stepwise multiple logistic regression was applied to determine the possible significant factors and the outcome of adequate immunogenicity to HBV vaccines. A $p$ value $<0.05$ was defined as statistically significant.

\section{RESULTS}

General characteristics. The general characteristics of BA patients and their matched controls are summarized in Tables 1 and 2. BA children had lower serum albumin, higher total bilirubin, and higher ALT levels. In the infant BA group, 10 children $(20 \%)$ had a serum total bilirubin level below 2 $\mathrm{mg} / \mathrm{dL}(1.1 \pm 0.5 \mathrm{mg} / \mathrm{dL})$ whereas another $40(80 \%)$ had serum total bilirubin level $\geq 2 \mathrm{mg} / \mathrm{dL}(16.5 \pm 10.8 \mathrm{mg} / \mathrm{dL})$. These jaundiced BA infants had lower body weight, body length, and serum albumin levels $(p=0.007,0.006$, and 0.03 , respectively) when compared with nonjaundiced BA infants.

Only four children $(17.4 \%)$ in the childhood BA group had serum total bilirubin level $\geq 2 \mathrm{mg} / \mathrm{dL}$ (median, $3.56 \mathrm{mg} / \mathrm{dL}$; range, $3.1-3.96 \mathrm{mg} / \mathrm{dL}$ ). There was no statistical difference in the clinical parameters, including body weight, body length, BMI, serum albumin, and ALT levels between jaundice and nonjaundiced childhood BA patients by Mann-Whitney U test.

Vaccination history of the study population. Thirty-eight BA infants (76\%) received the first dose of recombinant HBV vaccine before $7 \mathrm{~d}$ of age, $30(60 \%)$ received the second dose between 1 and 1.5 mo old, and $19(38 \%)$ received the third dose between 6 and 6.5 mo old. Only 12 BA infants (24\%) received all three doses of recombinant $\mathrm{HBV}$ vaccine on schedule.

Reasons for the delay of vaccination included prolonged hospitalization, chronic illness, and frequent infections. Among the BA infants, 10 (20\%) had HBsAg positive mothers, and eight received HBIG within $24 \mathrm{~h}$ of birth to prevent maternal transmission.

Serum anti-HBs level. The anti-HBs titers of BA patients and the control population of the infant and childhood groups are summarized in Table 3 . There was a significant difference between BA infants and their matched controls in the primary response to recombinant $\mathrm{HBV}$ vaccines $(p=0.001)$. There were more cases with inadequate immune response to $\mathrm{HBV}$ vaccine $(28 \%$ vs. $6 \%, \mathrm{OR}=6.09,95 \% \mathrm{CI}=1.73-21.20, p=0.006)$ in BA infants. Among those who had adequate immune response to recombinant $\mathrm{HBV}$ vaccine, there were fewer BA infants with serum anti-HBs above $100 \mathrm{IU} / \mathrm{L}$ after the third doses of HBV vaccine when compared with the control group $(58.3 \%$ vs. $83.0 \%, \mathrm{OR}=0.29,95 \% \mathrm{CI}=0.11-0.77, p=0.013)$.

Twelve $(30 \%)$ jaundiced $(n=40)$ and $2(20 \%)$ nonjaundiced BA infants $(n=10)$ had inadequate serum anti-HBs titer after complete vaccination. There was no obvious difference in the prevalence of inadequate anti-HBs titer between jaundiced and nonjaundiced BA infants $(30 \%$ vs. 20\%; risk difference, $0.1 ; 95 \% \mathrm{CI},-0.19$ to $0.39 ; p=0.70$ ) in our study. The prevalence of children with inadequate anti-HBs titers in

Table 1. General characteristics of biliary atresia (BA) infants and their matched control

\begin{tabular}{|c|c|c|c|c|c|}
\hline \multirow[b]{2}{*}{ Character } & \multicolumn{2}{|c|}{ BA group $(n=50)$} & \multicolumn{2}{|c|}{ Control group $(n=50)$} & \multirow[b]{2}{*}{$p$} \\
\hline & Mean & $95 \% \mathrm{CI}$ & Mean & $95 \% \mathrm{CI}$ & \\
\hline Age (yrs) & 0.9 & $0.9-1.0$ & 0.9 & $0.9-1.0$ & 0.95 \\
\hline Gender (F/M) & $31 / 19$ & & $31 / 19$ & & 1.00 \\
\hline \multicolumn{6}{|l|}{ Biochemical data } \\
\hline Albumin (mg/dL) & 3.5 & $3.3-3.6$ & 5.4 & $5.0-5.8$ & $<0.001$ \\
\hline $\operatorname{ALT}(\mathrm{mg} / \mathrm{dL})$ & 137.0 & $103.8-170.1$ & 29.6 & $24.3-34.8$ & $<0.001$ \\
\hline Total bilirubin $(\mathrm{mg} / \mathrm{dL})$ & 13.1 & $9.8-16.4$ & 0.4 & $0.3-0.5$ & $<0.001$ \\
\hline \multicolumn{6}{|l|}{ Nutritional status } \\
\hline Body weight (kg) & 8.0 & $7.5-8.6$ & 10.2 & $9.5-11.1$ & $<0.001$ \\
\hline Body length (cm) & 69.2 & $67.5-70.9$ & 75.6 & $72.9-78.3$ & $<0.001$ \\
\hline BMI $\left(\mathrm{kg} / \mathrm{m}^{2}\right)$ & 16.6 & $16.0-17.2$ & 17.8 & $17.2-18.5$ & 0.007 \\
\hline
\end{tabular}

ALT indicates alanine aminotransferase; BMI, body mass index. 
Table 2. General characteristics of the childhood biliary atresia (BA) group and their matched control

\begin{tabular}{|c|c|c|c|c|c|}
\hline \multirow[b]{2}{*}{ Character } & \multicolumn{2}{|c|}{ BA group $(n=23)$} & \multicolumn{2}{|c|}{ Control group $(n=23)$} & \multirow[b]{2}{*}{$p$} \\
\hline & Mean & $95 \% \mathrm{CI}$ & Mean & $95 \% \mathrm{CI}$ & \\
\hline Age (yrs) & 8.5 & $8.1-9.0$ & 8.5 & $8.1-9.0$ & 0.940 \\
\hline Gender (F/M) & $12 / 11$ & & $12 / 11$ & & 1.000 \\
\hline \multicolumn{6}{|l|}{ Biochemical data } \\
\hline Albumin (mg/dL) & 4.0 & $3.8-4.2$ & 5.8 & $5.5-6.2$ & $<.001$ \\
\hline $\operatorname{ALT}(\mathrm{mg} / \mathrm{dL})$ & 116.1 & $52.5-179.1$ & 15.5 & $13.4-17.7$ & 0.002 \\
\hline Total bilirubin $(\mathrm{mg} / \mathrm{dL})$ & 1.5 & $1.1-2.0$ & 0.6 & $0.5-0.6$ & $<0.001$ \\
\hline \multicolumn{6}{|l|}{ Nutritional status } \\
\hline Body weight (kg) & 26.3 & $23.1-29.6$ & 27.9 & $24.5-31.2$ & 0.490 \\
\hline Body length (cm) & 125.6 & $121.1-130.2$ & 129.6 & $126.2-130$ & 0.150 \\
\hline BMI $\left(\mathrm{kg} / \mathrm{m}^{2}\right)$ & 16.3 & $15.2-17.4$ & 16.3 & $15.3-17.5$ & 0.950 \\
\hline
\end{tabular}

ALT indicates alanine aminotransferase; BMI, body mass index.

Table 3. Humoral immune response against HBV after complete HBV immunization

\begin{tabular}{|c|c|c|c|c|c|}
\hline \multirow[b]{2}{*}{ Anti-HBs titers } & \multicolumn{2}{|c|}{ Biliary atresia } & \multicolumn{2}{|c|}{ Control population } & \multirow[b]{2}{*}{$p^{*}$} \\
\hline & Subject & Percentage & Subject & Percentage & \\
\hline Infant group (7-18 months) & $n=50$ & & $n=50$ & & 0.001 \\
\hline$<10 \mathrm{IU} / \mathrm{L}$ & 14 & 28.0 & 3 & 6.0 & \\
\hline $10-100 \mathrm{IU} / \mathrm{L}$ & 15 & 30.0 & 8 & 16.0 & \\
\hline$>100 \mathrm{IU} / \mathrm{L}$ & 21 & 42.0 & 39 & 78.0 & \\
\hline Childhood group (7-10 y) & $n=23$ & & $n=23$ & & 0.161 \\
\hline$<10$ IU/L & 9 & 39.2 & 7 & 30.4 & \\
\hline $10-100 \mathrm{IU} / \mathrm{L}$ & 7 & 30.4 & 13 & 56.5 & \\
\hline$>100 \mathrm{IU} / \mathrm{L}$ & 7 & 30.4 & 3 & 13.1 & \\
\hline
\end{tabular}

Serum anti-HBs titer below $10 \mathrm{IU} / \mathrm{L}$ is defined as inadequate immune response to HBV vaccine. Serum anti-HBs level between 10 and $100 \mathrm{IU} / \mathrm{L}$ is defined as low response and above $100 \mathrm{IU} / \mathrm{L}$ as good immunogenicity.

* Fisher's exact test was used to test the difference between biliary atresia and control groups in the variable humoral immune response to HBV vaccine.

the childhood BA group was not different from their matched control $(p=0.161)$.

Only $12(24 \%)$ BA infants $(n=50)$ received HBV immunization on-schedule in our study population. The response to HBV vaccine was not different between on- and out-ofschedule vaccines $(27.0 \%$ vs. $30.8 \%, \mathrm{OR}=0.83,95 \% \mathrm{CI}=$ $0.22-3.12, p=0.80)$ in this series.

Regarding serum anti-HBs as categorical outcomes, Fisher's exact test also showed no difference between on-schedule and out-of-schedule HBV vaccines in BA infants (Table $4, p=$ 0.255). Among BA infants with adequate and inadequate response, there was no statistical difference in the age of each HBV vaccine dose, the interval between each doses of HBV vaccine, nutritional status, serum ALT level, and total bilirubin levels (Tables 4 and 5). Serum anti-HBs titers of those who received HBIG $(n=8)$ were not different from those who did not receive $(n=42)(p>0.05)$. No significant difference was identified in the immunogenicity to $\mathrm{HBV}$ vaccines between the offspring of HBV infected mothers $(n=10)$ and those of HBV noninfected mothers $(n=40)(p>0.05)$.

Two BA infants received a booster dose of recombinant HBV vaccine after our assessment because of inadequate anti-HBs titers before LT. Both achieved adequate serum anti-HBs levels after the booster (one subject with initial anti-HBs $0.1 \mathrm{IU} / \mathrm{L}$ achieved $181.5 \mathrm{IU} / \mathrm{L}$, and the other from $8.6 \mathrm{IU} / \mathrm{L}$ to $18.7 \mathrm{IU} / \mathrm{L}$ after the booster dose).

Effects of nutritional status and $\mathrm{HBV}$ dose intervals on the anti-HBs level. BA patients with cholestatic jaundice had poorer nutritional status in our series when compared with the general population. At the same time, delayed HBV vaccination schedule might have also impaired the immunogenicity of the HBV vaccine. To exclude the possible confounding effects of poor protein-calorie status and untimely HBV vaccine schedule, we applied stepwise multiple logistic regressions to

Table 4. Humoral immune response in on- and out-of-schedule HBV vaccinees after complete HBV immunization in biliary atresia infants

\begin{tabular}{|c|c|c|c|c|c|}
\hline \multirow[b]{2}{*}{ Anti-HBs titers } & \multicolumn{2}{|c|}{ On-schedule vaccines $(n=12)$} & \multicolumn{2}{|c|}{ Out-of-schedule vaccines $(n=38)$} & \multirow[b]{2}{*}{$p^{*}$} \\
\hline & Subject & Prevalence $(\%)$ & Subject & Prevalence $(\%)$ & \\
\hline$<10 \mathrm{IU} / \mathrm{L}$ & 3 & 25.0 & 11 & 28.9 & \\
\hline$>100 \mathrm{IU} / \mathrm{L}$ & 3 & 25.0 & 18 & 47.4 & 0.255 \\
\hline
\end{tabular}

Serum anti-HBs titer below $10 \mathrm{IU} / \mathrm{L}$ is defined as inadequate immune response to HBV vaccine. Serum anti-HBs level between 10 and $100 \mathrm{IU} / \mathrm{L}$ is defined as low response and above $100 \mathrm{IU} / \mathrm{L}$ as good immunogenicity.

Those who received the first dose before 7-day-old, the second dose between 1 and 1.5 month-old, and the third dose between 6 and 6.5 month-old were defined as "on-schedule" HBV vaccinees. Others were defined as "out-of-schedule" HBV vaccines.

* Fisher exact test was used to test the difference between on-schedule and off-schedule BA infants in the variable humoral immune response to HBV vaccine. 
Table 5. Characteristics between adequate (anti-HBs $\geq 10 \mathrm{IU} / \mathrm{L}$ ) and inadequate (anti-HBs $<10 \mathrm{IU} / \mathrm{L}$ ) HBV vaccine responders of BA infants

\begin{tabular}{|c|c|c|c|c|c|}
\hline & \multicolumn{2}{|c|}{ Inadequate $(n=14)$} & \multicolumn{2}{|c|}{ Adequate $(n=36)$} & \multirow[b]{2}{*}{$p$ value ${ }^{*}$} \\
\hline & Median & Range & Median & Range & \\
\hline Age (month-old) & 12 & $7-18$ & 11.5 & $7-18$ & 0.777 \\
\hline \multicolumn{6}{|l|}{ Nutrition status } \\
\hline Body weight (kg) & 8.4 & $5.5-9.7$ & 8.0 & $5.1-15.0$ & 0.697 \\
\hline Body length (cm) & 67 & $63-78$ & 69 & $56-92$ & 0.650 \\
\hline BMI $\left(\mathrm{kg} / \mathrm{m}^{2}\right)$ & 16.0 & $13.3-22.0$ & 16.2 & $12.1-20.8$ & 0.574 \\
\hline \multicolumn{6}{|l|}{ Blood test (mg/dL) } \\
\hline Albumin & 3.7 & $2.3-4.5$ & 3.5 & $1.3-4.8$ & 0.392 \\
\hline ALT & 116.5 & $16-537$ & 102.5 & $24-506$ & 0.370 \\
\hline Total bilirubin & 9.6 & $1.2-24.5$ & 14.1 & $0.5-49.6$ & 0.552 \\
\hline \multicolumn{6}{|l|}{ HBV doses (day-old) } \\
\hline First dose & 3 & $3-31$ & 5 & $2-87$ & 0.427 \\
\hline Second dose & 38 & $32-184$ & 40 & $29-183$ & 0.309 \\
\hline Third dose & 210.5 & $186-332$ & 215.5 & $181-394$ & 0.779 \\
\hline \multicolumn{6}{|l|}{ HBV doses interval (days) } \\
\hline First and second doses & 33 & $29-181$ & 32.5 & $26-180$ & 0.180 \\
\hline Second and third doses & 154 & $83-234$ & 171.5 & $60-327$ & 0.320 \\
\hline First and third doses & 202 & $183-329$ & 207 & $94-387$ & 0.948 \\
\hline
\end{tabular}

* Mann-Whitney U test was applied for the non-parametric statistical analysis.

analyze the correlation between response to HBV vaccine and BMI, serum albumin level, body weight, body length, serum bilirubin levels, dose intervals, and the presence or absence of $\mathrm{BA}$ in the infant study group.

A negative correlation between the diagnosis of BA and vaccine response was identified (coefficient $=-1.81$; $\mathrm{SE}=$ $0.67 ; R^{2}=10.07 \% ; 95 \% \mathrm{CI}=-3.13$ to $\left.-0.49 ; p=0.007\right)$. However, the correlation coefficient of serum albumin level, bilirubin level, HBV vaccine dose interval, and parameters of nutritional status with serum anti-HBs level were not significant $(p>0.05)$.

\section{DISCUSSION}

Poor humoral immune response to various vaccines including Haemophilus influenzae type B-polyribosylribitol phosphate vaccine and $\mathrm{HBV}$ vaccine have been reported in BA patients $(3,13)$. At the same time, poor immunogenicity to HBV vaccine immunization has also been noted in several immunocompromised conditions, such as end stage renal disease, human immunodeficiency virus infection, and alcoholic liver disease $(11,14,15)$.

Adequate humoral immune response to $\mathrm{HBV}$ vaccine is mainly a T-lymphocyte dependent immune process and impairment of T-lymphocyte function adversely affects immune response $(3,14,16)$. Impaired $\mathrm{T}$-lymphocyte proliferative function has been demonstrated in cholestatic animal models, and in cholestatic liver diseases such as BA by our previous study $(12,17,18)$. The phenomenon of poor primary immunogenicity to recombinant $\mathrm{HBV}$ vaccines in BA patients may partly be due to T-lymphocyte defect which was also observed in patients with end-stage renal disease and AIDS $(14,16)$.

Routine $\mathrm{HBV}$ vaccination schedules were delayed in many BA patients because of frequent hospitalizations and infections. Our analysis does not demonstrate significant difference in the effectiveness of recombinant HBV vaccines between on- and out-of-schedule HBV vaccines.
There was no difference in the timing of each HBV dose and in dose-intervals between BA infants with and without adequate anti-HBs titers. Logistic regression analysis also did not identify any association between the adequacy of humoral immune response between HBV doses and doses interval. Thus, a delay in $\mathrm{HBV}$ routine schedule may not be a significant confounding factor in poor immunogenicity to recombinant $\mathrm{HBV}$ vaccine in BA patients.

Chronic malnutrition is another possible contributing factor that depresses systemic immune function (19). To exclude the possible effect of poor nutritional status on the adequacy of $\mathrm{HBV}$ vaccine response, multiple logistic regression statistics was applied to see the correlation of these factors. The analysis showed no correlation between nutritional status and serum anti-HBs titers. However, limited cases of jaundiced BA children (7-10 y of age) were enrolled in our series, which disabled us to evaluate the effects of long lasting jaundice on the natural waning of serum anti-HBs titers in jaundiced BA children.

As a cross-sectional study, we can only observe the prevalence of serum anti-HBs titers at two different age levels in our study subjects. The age-specific prevalence of individuals with adequate serum anti-HBs titers between BA children and healthy control is similar in our childhood group, but differed in our infant groups. It is reasonable to deduce that the primary immune response between BA infants and healthy infants differed in our series. Serum anti-HBs titers waning after vaccination has been observed in the normal population (20,21). In our childhood group, all of the study subjects are negative for anti$\mathrm{HBc}$ and all received only three doses of recombinant $\mathrm{HBV}$ vaccine at infancy. Thus, subjects with adequate anti-HBs titers enrolled in the childhood group (both BA and control group) must acquire their immunity against $\mathrm{HBV}$ after the scheduled HBV immunization in infancy. At 7-10 y of age, BA children's humoral immunity to HBV vaccine is similar to the controls' should they receive standard vaccination. 
In conclusion, our study demonstrates a poor primary immunogenicity to $\mathrm{HBV}$ vaccines in BA infants after the standard three doses of recombinant HBV vaccines. However, once adequate humoral immunity against $\mathrm{HBV}$ is achieved, the long-term protection against HBV in BA patients is comparable with the general population. Nutritional status and delayed HBV schedule are not confounding factors in HBV vaccine immunogenicity. Maintaining timely HBV vaccination should be encouraged.

\section{REFERENCES}

1. Hoofnagle JH 2004 Biliary atresia research consortium (BARC). Hepatology 39:891

2. Hung PY, Chen CC, Chen WJ, Lai HS, Hsu WM, Lee PH, Ho MC, Chen TH, Ni YH, Chen HL, Hsu HY, Chang MH 2006 Long-term prognosis of patients with biliary atresia: a 25 year summary. J Pediatr Gastroenterol Nutr 42:190-195

3. Sokal EM, Ulla L, Otte JB 1992 Hepatitis B vaccine response before and after transplantation in 55 extrahepatic biliary atresia children. Dig Dis Sci 37:1250-1252

4. Chen DS, Hsu NH, Sung JL, Hsu TC, Hsu ST, Kuo YT, Lo KJ, Shih YT 1987 A mass vaccination program in Taiwan against hepatitis B virus infection in infants of hepatitis B surface antigen-carrier mothers. JAMA 257:2597-2603

5. Chen HL, Chang MH, Ni YH, Hsu HY, Lee PI, Lee CY, Chen DS 1996 Seroepidemiology of hepatitis B virus infection in children: ten years of mass vaccination in Taiwan. JAMA 276:906-908

6. Ni YH, Chang MH, Huang LM, Chen HL, Hsu HY, Chiu TY, Tsai KS, Chen DS 2001 Hepatitis B virus infection in children and adolescents in a hyperendemic area: 15 years after mass hepatitis B vaccination. Ann Intern Med 135:796-800

7. Ni YH, Huang LM, Chang MH, Yen CJ, Lu CY, You SL, Kao JH, Lin YC, Chen HL, Hsu HY, Chen DS 2007 Two decades of universal hepatitis B vaccination in Taiwan: impact and implication for further strategies. Gastroenterology 132:12871293

8. Ho MC, Wu YM, Hu RH, Ko WJ, Yang PM, Lai MY, Lin MH, Lin HY, Lee PH 2004 Surgical complications and outcome of living related liver transplantation. Transplant Proc 36:2249-225
9. Lin CC, Chen CL, Concejero A, Wang CC, Wang SH, Liu YW, Yang CH, Yong CC, Lin TS, Chiang YC, Jawan B, Huang TL, Cheng YF, Eng HL 2007 Active immunization to prevent de novo hepatitis $\mathrm{B}$ virus infection in pediatric live donor liver recipients. Am J Transplant 7:195-200

10. Taylor RM, Cheeseman P, Davenport M, Tizzard SA, Goldblatt D, Mieli-Vergani G Hadzic N 2003 Humoral immunity in children with biliary atresia splenic malformation syndrome. Eur J Pediatr 162:539-540

11. Collier AC, Corey L, Murphy VL, Handsfield HH 1988 Antibody to human immunodeficiency virus (HIV) and suboptimal response to hepatitis B vaccination. Ann Intern Med 109:101-105

12. Wu JF, Chiang BL, Chen HL, Lai HS, Chang MH, Ni YH 2006 Impaired T lymphocyte proliferation function in biliary atresia patients with chronic cholestatic jaundice after a Kasai operation. Pediatr Res 60:602-606

13. Rosenthal P, Wong V, Ross LA, Kim KS 1990 Immunogenicity of Haemophilus influenzae type $\mathrm{B}$ vaccines in children with hepatoportoenterostomies. J Pediatr Gastroenterol Nutr 11:201-204

14. Lacson E, Teng M, Ong J, Vienneau L, Ofsthun N, Lazarus JM 2005 Antibody response to Engerix-B and Recombivax-HB hepatitis B vaccination in end-stage renal disease. Hemodial Int 9:367-375

15. Mendenhall C, Roselle GA, Lybecker LA, Marshall LE, Grossman CJ, Myre SA, Weesner RE, Morgan DD 1988 Hepatitis B vaccination. Response of alcoholic with and without liver injury. Dig Dis Sci 33:263-269

16. Veiga AP, Casseb J, Duarte AJ 2006 Humoral response to hepatitis B vaccination and its relationship with $\mathrm{T}$ CD45RA+(naïve) and CD45RO+(memory) subsets in HIV-1-infected subjects. Vaccine 24:7124-7128

17. Parks RW, Halliday MI, McCrory DC, Erwin P, Smye M, Diamond T, Rowlands BJ 2003 Host immune responses and intestinal permeability in patients with jaundice. Br J Surg 90:239-245

18. Thompson RL, Ranjbar S, Rowlands BJ 1993 T-lymphocyte transformation in experimental obstructive jaundice: the role of serum-suppressive factors. World J Surg 17:783-785

19. Law DK, Dudrick SJ, Abdou NI 1973 Immunocompetence of patients with protein calorie malnutrition. Ann Intern Med 79:545-550

20. Shih HH, Chang MH, Hsu HY, Lee PI, Ni YH, Chen DS 1999 Long-term immune response of universal hepatitis $\mathrm{B}$ vaccination in infancy: a community-based study in Taiwan. Pediatr Infect Dis J 18:427-432

21. Lin YC, Chang MH, Ni YH, Hsu HY, Chen DS 2003 Long-term immunogenicity and efficacy of universal hepatitis B virus vaccination in Taiwan. J Infect Dis 187:134-138 